\title{
Get Involved: Clarissa Yablinsky, Women in Materials Science and Engineering Committee
}

\section{Kelly Zappas}

"Get Involved" is a recurring End Notes feature that spotlights the work of TMS volunteers and shows the wide range of activities available through TMS. This month features Clarissa Yablinsky, postdoctorate research associate at the University of Wisconsin and a member of the TMS Women in Materials Science and Engineering Committee. The committee develops TMS programs and activities that address the professional needs and aspirations of women actively pursuing a career in materials science and engineering. The committee also seeks to promote materials engineering as an attractive career choice and opportunity for young women and TMS as their professional society home.

Q. How did you first become involved with the TMS Women in Materials Science and Engineering Committee? What made you decide to join this group?

A. I first became involved in the Women in Science Committee when a couple of my women colleagues invited me to attend the committee meeting at the TMS 2010 Annual Meeting in Seattle. I decided to join because it gives me a great opportunity to meet other women who are scientists, and gives me a chance to help others with my experiences.

Q. Had you ever volunteered with TMS before you joined the Women in Materials Science and Engineering Committee? In what roles?

A. In undergrad, I was the chair for our school's student chapter. I have also lead discussions at Student Chapter Development Conferences at Materials Science \& Technology (MS\&T) meetings.

Q. What is your current role on the Women in Materials Science and Engineering Committee? As a member of the committee, what sorts of volunteer work have you done?

A. Currently, I am a member of the Breakfast Subcommittee in addition to being a general member of the committee. The subcommittee plans the agenda for the Women in Science breakfast, which is held each year at the TMS Annual Meeting. The Breakfast Subcommittee is responsible for deciding on discussion topics and trying to have enough diversity in topics from year to year.

Q. Is the Committee looking for new members? Is it open to anyone?

A. The Women in Science Committee is always looking for new members, in all stages of their career, both male and female.

Q. Why would you encourage members to join?

I would encourage members to join this committee because it is focused on promoting women in science and supporting women in all of our roles.

Q. If a member was interested in volunteering with the Women in Materials Science and Engineering Committee, how could they get involved?

A. The Women in Science Committee meets at both the MS\&T and TMS Annual meetings. The meetings are normally during the week, and everyone is welcome to join. Otherwise, they can send an e-mail to our TMS staff liaison, Bryn Simpson, at bsimpson@tms.org, and she can add them to the e-mail list.

Q.Why doyou volunteerwith TMS? Have your volunteer experiences helped you professionally?

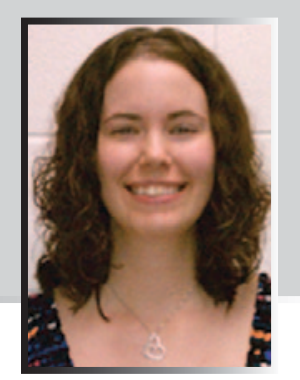

A. I volunteer with TMS because I am interested in helping to shape my own future. Volunteering helps me professionally because it is a great way to meet other motivated members, who share similar career and research interests.

Q. Do you currently volunteer with any other TMS committees or activities?

A. I am also a member of the Nuclear Materials Technical Committee, which I just joined at this past TMS Annual Meeting in San Diego.

Q. How much time do you commit to your volunteer activities? Is it difficult to balance your work and volunteer activities?

A. Most of the time I volunteer is during the annual meetings, with a few e-mails or teleconferences leading up to an event. Balancing activities has, so far, been easy for me.

Kelly Zappas is a contributing writer for TMS.

If you are interested in participating in the the Women in Materials Science and Engineering Committee, contact Bryn Simpson at bsimpson@TMS.org for information. And if you know of a TMS member who should be featured in a future "Get Involved" column, contact Kelly Zappas at kzappas@tms.org. 